\title{
Management Education Benchmarking Designing Customized And Flexible MBA Programs
}

Owen P. Hall, Jr., (E-mail: Owen.Hall@pepperdine.edu), Pepperdine University Terry W. Young, (E-mail: terry.young@pepperdine.edu), Pepperdine University

\begin{abstract}
To meet the challenges of the $21^{\text {st }}$ century B-schools are revising curriculum, delivery and outcome assessment modalities. Today, the proportion of electives and other specialty offerings in many MBA programs now constitutes more than 50\% of the total curriculum. However, this focus on customization, integration and flexibility is not without its own challenges including quality assurance and implementation. Benchmarking, which involves the assessment of a variety of inputs including student satisfaction, the business community and the accreditation process represents, one approach for meeting these challenges. The purpose of this paper is twofold: 1) to benchmark trends and challenges in MBA programs geared towards the working adult and 2) to outline a process for implementing more flexibility and customization in MBA curriculums. The results of a student satisfaction survey of MBA graduates revealed that a customized curriculum yielded greater insights and enhanced job related capabilities than a generalized curriculum.
\end{abstract}

\section{INTRODUCTION}

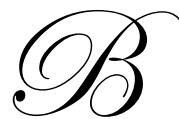

usiness schools are under increasing pressure to enact significant curriculum reforms within the traditional educational process. These dynamics can be traced to a variety of phenomena which include the growth of overseas educational institutions, visa restrictions, Internet based programs, and changing student demographics. As a result of these forces, the general pedagogical direction in management education is moving increasingly towards a learning-centric perspective (Driver, 2002). With working professionals returning to the classroom in ever increasing numbers the roadmap to effective learning in this environment is a customized and flexible curriculum. This is particularly the case for fully employed adults enrolled in an MBA program. A customized curriculum is one that is tailored to the background and work related requirements of the student. While the level of customization varies, the proportion of electives and other specialty offerings in many MBA programs is now greater than $50 \%$ of the total curriculum. One learning stratagem that supports a customized and flexible curriculum design philosophy is the Instructional Management System (IMS) cooperative initiative (Graves, 1999). This initiative is designed to promote systematic thinking regarding the delivery of higher education, to improve learning outcomes and to increase return on instruction investments. Specific principles of the IMS initiative are as follows: 1) education involves more than a single course; 2) a course is more than content; 3) content is more important that lecture notes; 4) convenience is a priority and 5) quality assurance requires an integrated learning approach. One approach to help facilitate the introduction of the IMS initiative in curriculum design is through the process known as benchmarking.

\section{BENCHMARKING}

Benchmarking, first introduced by Xerox in the mid 1970's, has seen growing usage throughout schools of business (Stephens, 2001; Amin, 2003). Basically benchmarking is a process for supporting continuous improvement through a combination of internal review and external assessment. Among other things benchmarking brings out new methods, ideas and systems to improve curriculum effectiveness. One definition that captures the essence of benchmarking as related to management education curricula is as follows (Harrington, 1996): 
"A systematic way to identify, understands, and creatively evolves superior products, services, designs, equipment, processes, and practices to improve your organization’s real performance.”

The basic steps common to most benchmarking processes as related to curriculum development include the following:

- Identify key variables and factors in the curriculum.

- Identify the "best-in-class" b-schools having a similar mission statement.

- $\quad$ Characterize the performance of each organization using the key variables.

- $\quad$ Measure the performance of your school.

- $\quad$ Develop an action plan for improving key performance metrics based on leapfrogging.

- $\quad$ Implement the plan including provisions for ongoing monitoring and revision.

Benchmarking enables curriculum designers to develop significantly more viable designs using a systematic approach that takes into account the various stakeholders such as students, alumni, the business community, accrediting body, faculty and administrators. Typically, benchmarking involves both informal and formal dialogue with these stakeholders. Internet based surveys provide a cost-effective approach for supporting an ongoing formal dialogue process. However, benchmarking involves more than simply looking inward. . Identifying those b-schools, with a similar mission statement, deemed to be engaged in best practices can also contribute to developing an effective plan. The idea is to identify the very best practices on a worldwide basis. This characterization can be made through contacting accrediting bodies, like the Association to Advance Collegiate Schools of Business (AACSB), and through an extensive literature review (Aupperle, 2003). Leapfrogging, a key outcome of the best practices assessment, is a construct by which progress is made in large jumps instead of in small increments. Inventiveness, technological innovation and ingenuity are the building blocks of leapfrogging. For example, many universities are adopting the Bto-C (Business to Consumer) commercial model developed in the late 1990s for delivering content in a more costeffective manner (Shih, 2003; Smilor, 2004). Specific technological based applications include webcasting, intelligent tutors, blogging and virtual tours (Changchit, 2003; Pettijohn, 2002). Curriculum.

Figure 1 Presents An Overview Of The Benchmarking Process Used In Designing A Customized MBA

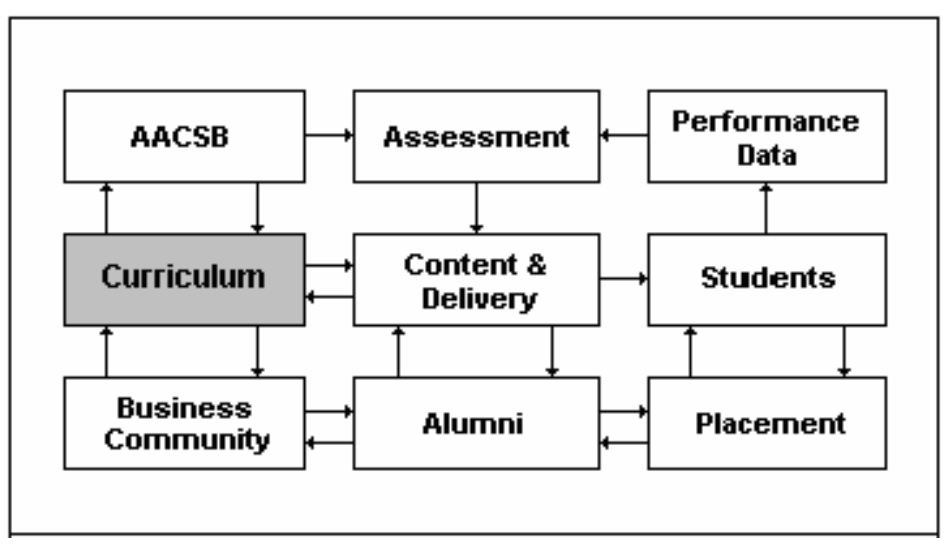

Figure 1 - MBA Program Benchmarking Process

The design process took about 18 months to complete and involved the list of stakeholders featured in Figure 1. A comparison of the new "customized" curriculum with the old "generalized" curriculum is highlighted in Table 1 along with a comparison with the curriculum at Loyola Marymount University (Los Angeles), College of Business 
Administration, a school with a similar mission statement. The latter profile is included to emphasize the importance of using a combination of both an internal and external assessment process.

Table 1 - MBA Curriculum Comparison

\begin{tabular}{|c|c|c|c|}
\hline $\begin{array}{l}\text { Curriculum } \\
\text { Component }\end{array}$ & Generalized MBA & Customized MBA & LMU MBA* \\
\hline Core & 40 & 32 & 27 \\
\hline Electives & 4 & 12 & 18 \\
\hline Integration & 5 & 8 & 9 \\
\hline Total & 49 & 52 & 54 \\
\hline \% Non-Core/Total & $\mathbf{1 8}$ & $\mathbf{3 8}$ & $\mathbf{5 0}$ \\
\hline Minimum Completion Time (mo.) & 24 & 24 & 21 \\
\hline
\end{tabular}

*Loyola Marymount University, College of Business Administration (2005)

A key metric from Table 1 is the significant increase in the proportion of "non-core" courses to the total (i.e., the increase in customization). As can been seen the percentage more than doubled from the "generalized" to the "customized" curriculum even though there was less than a $10 \%$ increase in the total number of program units. The threefold increase in electives between the "generalized" and "customized" curricula allows for the introduction of an emphasis or specialization. While AACSB guidelines do not specify a minimum of units to qualify for an emphasis (the actual number is left up to the school in keeping with its mission statement), the benchmarking process indicated that 12 units represented a manageable arrangement. In the new "customized" program, emphases are being offered in finance, organizational leadership, globalization, and entrepreneurship. Students can also opt for a non-emphasis focus (generalized) where they can select course work from a variety of disciplines. New aspects of the integrating learning experience include:

- $\quad$ Contemporary Issues in Business and Management - A series of symposiums focusing a variety of topical issues including ethics, entrepreneurship, creativity, supply chain management, and globalization. A primary goal of these symposiums is to acquaint the student, via business experts, with the complexities of modern business practice.

- Integration in Business Operations (Tactical) - A mid-curriculum point business simulation that is designed to integrate the basic management functions from the core component of the program. The team oriented simulation is designed to underscore the importance of business planning and collective problem solving.

- Global Study Tours Initiative - Site visit to internationally recognized companies and government organizations (e.g., European Commission) in selected regions for a hands-on experience at business trends and management strategies. One of the goals of this experience is for the student to obtain insights into the culture and history of the region which impacts local business practices.

Management topics such as ethics, entrepreneurship, creativity and globalization are often difficult to cover in a single course due the multi-disciplinary nature of the subject matter (Pinard, 2005). The training and development of effective business leaders calls for a curriculum that blends both the technical (e.g., finance) and behavioral (e.g., ethics) dimensions of management (Scanlan, 2004). Multi-disciplinary symposiums provide one approach for addressing these requirements. In a similar vain, simulations have been found to be particularly effective in developing individual systemic skills on complex issues such as running a business (Aquino, 2005). The development of team cohesion is also a typical objective of most MBA programs. Recent evidence has shown that students engaged in business simulations retain about $75 \%$ of the instructional content compared to $5 \%$ for lectures, $20 \%$ for audiovisual presentations, and $50 \%$ for discussion groups (Johne, 2003). Global study tours are holistic learning experiences that introduce the student to the many facets of international markets. A well designed study tour should provide the student with insights into international business practices as well as regional macro-level economic environments. The study tour can also serve as a curriculum integrator and to underscore the level of diversity of the global marketplace (Kathawala, 2002). The placement of the field trip within the program and the pre-departure 
orientation should both help enhance the overall learning experience for the students (Cotner, 2003). Many professional students find it difficult to participate in an extended study tour due to work demands. A one-week program in a country where international business is widely practice provides an ideal compromise. A variety of first class study tours distributed throughout the academic year should be made available to provide the student with maximum choice.

As can be seen from the foregoing discussion, the new curriculum incorporates both significant customization as well as integration. After pilot testing at one satellite campus the curriculum was deployed on a school wide basis. The size of the student body is approximately 1,500 distributed over six campuses. A survey assessment was then made to compare student reaction to both programs. This represents the final step in the benchmarking process (i.e., monitor performance). Specifically, the following null hypotheses were developed based on the foregoing discussion.

Hypothesis 1: A customized MBA program compared to a generalized MBA program does not result in deeper knowledge and more job related capabilities.

Hypothesis 2: A customized MBA program compared to a generalized MBA program does not result in a change in overall student perceived quality.

Hypothesis 3: There was no difference in student perceived quality based on the particular emphasis track in the customized MBA program.

Hypothesis 4: There was no difference in perceived student satisfaction based on the particular emphasis track in the customized MBA program.

The results from the hypothesis testing are presented in the following section.

\section{DATA ANALYSIS}

The database consisted of student demographic and preference information from the old "generalized" program and the new "customized" program. The characterized of both of these programs are described in Table 1. After a pre-test, a 30-question survey was distributed over the Internet to approximately 600 students nearing graduation from both programs. The resultant sample size was 352. Table 2 presents some descriptive statistics for the two MBA programs.

Table 2 - Comparison Of Selected Descriptive Statistics

\begin{tabular}{|c|c|c|c|}
\hline Variable & $\begin{array}{c}\text { Generalized } \\
\text { MBA (N=81) }\end{array}$ & $\begin{array}{c}\text { Customized } \\
\text { MBA (N=271) }\end{array}$ & Statistical Difference \\
\hline Age at Graduation (yrs) & 34.4 & 33.4 & No ( $\mathrm{p}=.84)$ \\
\hline Gender (\% Female) & 42 & 35 & No $(\mathrm{p}=.23)$ \\
\hline
\end{tabular}

Table 3 provides a sampling of selected survey preference questions and averages. The preferences were measured on a standard Likert one to five scale ( 5 = strongly agree).This data shows, for example, the program made me a better leader item was ranked first across both curriculums while the program provided consistent quality item was ranked lasted. A standard Wilcoxon nonparametric test of the two curriculums showed no statistical difference in ranking. 
Table 3 - Selected Preference Assessment

(5=strongly agree)

\begin{tabular}{|c|c|c|}
\hline Question & Generalized MBA & Customized MBA \\
\hline Program made me a better leader & 4.05 & 3.08 \\
\hline Program made me a better manager & 3.91 & 3.99 \\
\hline Program gave me deeper knowledge & 3.73 & 3.80 \\
\hline Program was satisfactory & 3.72 & 3.47 \\
\hline Program provided value & 3.35 & 2.89 \\
\hline
\end{tabular}

Figure 3 presents the emphasis distribution for the customized program from the survey data. As can be seen the finance emphasis represents the largest component. The demand for elective courses varies considerably from trimester to trimester which tends to administratively complicate the implementation of the emphasis tracks. This problem situation was not the case for the "generalized" curriculum. Technology can help ameliorate the varied demand for emphasis across multiple campuses. Specifically, the use of web based broadcasting allows the lecture, course content (e.g., cases) and student team presentations to be distributed via the Internet to several campuses simultaneously. This technology based approach can insure that a particular emphasis is delivered which might not be the case if the enrollments at each campus were insufficient to offer the course.

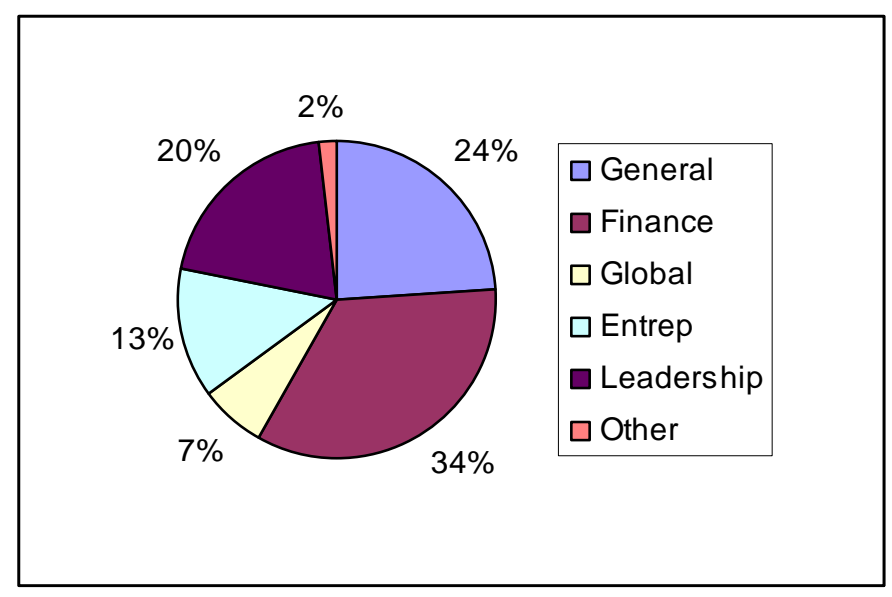

Figure 3 - Emphasis Distribution By Area

Table 4 summarizes the hypothesis testing results. The first hypothesis suggests that a "customized” MBA program compared to a "generalized" MBA program does not result in deeper knowledge and more job related capabilities. The results do not support this hypothesis $(\mathrm{p}=.01)$. The second hypothesis that a customized program compared to a generalized program does not result in a change in overall student perceived quality cannot be rejected $(p=.70)$. The third and fourth hypotheses were designed to test for consistency between the various elective tracks. A one-way ANOVA model was used to assess hypotheses \#3 and \#4. Hypothesis 3 states that there was no difference in student perceived quality based on the particular emphasis track in the customized MBA program. This hypothesis cannot be rejected $(\mathrm{p}=0.30)$. The final hypothesis states that a there was no difference in perceived student satisfaction based on the particular emphasis track. The results support this hypothesis $(\mathrm{p}=0.66)$. 
Table 4 - Hypothesis Testing Summary

\begin{tabular}{|c|c|c|}
\hline Hypothesis & p-value & Conclusions \\
\hline 1 & 0.01 & Customized curriculum yields greater insights \\
\hline 2 & 0.70 & No difference in perceived quality between curriculums \\
\hline 3 & 0.32 & No difference in perceived quality across elective tracks \\
\hline 4 & 0.66 & No difference in satisfaction across elective tracks \\
\hline
\end{tabular}

The survey data for the "customized" program was further evaluated using correlation analysis. Table 5 presents zero-order correlation coefficients for the database.

Table 5 - Zero-Order Correlation Matrix For Customized Program (Pearson)

\begin{tabular}{|l|c|c|c|c|c|c|c|c|}
\hline Variables & $\mathbf{1}$ & $\mathbf{2}$ & $\mathbf{3}$ & $\mathbf{4}$ & $\mathbf{5}$ & $\mathbf{6}$ & $\mathbf{7}$ & $\mathbf{8}$ \\
\hline 1.Years & 1 & & & & & & & \\
\hline 2. Gender & -.05 & 1 & & & & & & \\
\hline 3. Age & $.14^{*}$ & -.11 & 1 & & & & & \\
\hline 4. Better Manager & -.08 & -.08 & .09 & 1 & & & & \\
\hline 5. Better Leader & -.00 & -.08 & $.19^{*}$ & $.65^{*}$ & 1 & & & \\
\hline 6. Deeper Insights & -.02 & -.04 & $.17^{*}$ & $.28^{*}$ & $.30^{*}$ & 1 & & \\
\hline 7. Program Satisfaction & -.03 & .04 & $.13^{*}$ & $.18^{*}$ & $.24^{*}$ & $.73^{*}$ & 1 & \\
\hline 8. Program Quality & -.01 & -.04 & $.15^{*}$ & $.33^{*}$ & $.31^{*}$ & $.18^{*}$ & $.22^{*}$ & 1 \\
\hline
\end{tabular}

*Significant at 0.05

Among other things, the correlation data revealed the following:

- $\quad$ Older students compared to younger students experienced a higher level of program satisfaction $(\mathrm{r}=0.13$, $\mathrm{p}=$ 0.04)

- $\quad$ Students that viewed that the program made them a better leader compared to those students who did not, reported a higher level of program quality $(r=0.31, p=0.00)$

- $\quad$ Students that viewed that the program made them a better manager compared to those students who did not, reported that the program provided deeper insights $(r=0.28, p=0.00)$

- $\quad$ Students that viewed that the program provided deeper insights compared to those students who did not, had a higher level of program satisfaction $(r=0.73, \mathrm{p}=0.00)$

\section{CONCLUSIONS}

The use of customized and flexible curriculum for management education is on the rise. A well designed customized curriculum offers the student a higher degree of ownership and collaboration that can be more effective than a more generalized curriculum. A customized curriculum, like the one outlined in this paper, represent a long sought solution to the ongoing challenges of associated with adult management education. Working professionals can enjoy a more dynamic, personal and scaleable experience for continuous learning in a flexible learning environment. Customization also provides the working professional with a purposeful entry to the Internet and to online resources. Through the Internet the student is exposed to a new era of learning technologies that helps develop new managerial capabilities via virtual arrangements.

Benchmarking represents one paradigm for assisting in the development and implementation of a customized MBA curriculum. Some key issues to consider in applying the benchmarking process to curriculum design include:

- $\quad$ Assess the proposed program in light of the school's mission and objectives

- $\quad$ Evaluate the proposal's rationale including delivery potential 
- $\quad$ Encourage interdisciplinary linkages while minimizing duplications

- $\quad$ Estimate student learning outcomes and design a plan to monitor performance

- $\quad$ Forecast staffing and technology resource requirements

The results of a student satisfaction survey, conducted at the time of graduation, indicated that a benchmarked designed customized MBA program did provide deeper insights and more job related capabilities than does a traditional generalized MBA program. Furthermore, the survey analysis revealed that there was no perceived reduction in overall program quality with the customized curriculum. This outcome is of real significance since customized curriculum are more complex and thereby more difficult to administer and deliver. Web based delivery systems such as intelligent tutors, webcasting, blogging and virtual experiences offer considerable promise for assisting in both the design and the delivery of an increasingly personalized learning experience in management education (Cheung, 2003)..

\section{REFERENCES}

1. Amin, M. and Amin, N. 2003. Benchmarking learning outcomes of undergraduate business education. Benchmarking: An International Journal, 10 (6), 538.

2. Aquino, K. and Serva, M., 2005, Using a dual role assessment to improve group dynamics and performance. Journal of Management Education, 29 (1), 17.

3. Aupperle, K. and Dunphy. 2003. Benchmarking financial assessment in the strategy course: A qualitative and quantitative template. Journal of Education for Business, 78 (4), 205.

4. Changchit, C. 2003. An investigation into the feasibility of using an internet-based intelligent system to facilitate knowledge transfer. Journal of Computer Information Systems, 43, (4), 91.

5. Cheung, B. 2003. An intelligent tutoring system in web-based adult education. Journal of Systems and Software, 68 (1), 11.

6. Cotner, J. and Jones, R.; Kashlak, R. 2003. Effectively Integrating an International Field Study into the EMBA Curriculum. Journal of Teaching in International Business, 15 (1), 5.

7. Driver, M. 2002. Investigating the benefits of web-centric instruction for study learning: An exploratory study of an MBA course. Journal of Education for Business, 77 (4), 238.

8. Graves, W. 1999. The instructional management system cooperative: converting random acts of progress into global progress. Educom Review, 34 (6), 32.

9. Harrington, J. 1996. High performance benchmarking: 20 steps to success. New York: McGraw-Hill.

10. Johne, M. 2003. Virtual environments. CMA Management, 76 (10), 28.

11. Kathawala, Y. and Abdou, K.; Elmuti, D. 2002. The global MBA: a comparative assessment for its future. Journal of European Industrial Training, 26 (1), 14.

12. Pettijohn, J. 2002. Virtual Tours - A tool for enhancing and enlivening the international business class. Journal of Business Education, 75 (5), 291.

13. Pinard, M. and Allio, R. 2005. Innovations in the classroom: Improving the creativity of MBA students. Strategy \& Leadership, 33 (1), 49.

14. Scanlan, L. 2004. So you want to be a CFO? Healthcare Financial management, 59 (5), 70.

15. Shih, Y., 2003. A survey of distance education challenges and technologies. International Journal of Distance Learning Technologies, 1 (1), 1.

16. Smilor, R. and Matthews, J. 2004. University venturing: Technology transfer and commercialization in higher education. International Journal of Technology Transfer \& Commercialization, 3 (1), 111.

17. Stephens, C. and O'Hara, M. 2001. Benchmarking the required information systems course in AACSB accredited MBA programs: An analysis of course content and process. The Journal of Computer Information Systems, 41 (4), 38. 
NOTES 